\title{
10
}

\section{Direito ao esquecimento na internet: consequências da memória virtual}

\author{
Efraim Leite de Lima \\ Graduado em Direito pelo Centro Universitário de João Pessoa (UNIPÊ). Pós-graduando em \\ Direito Civil e Processo Civil. E-mail: efraimlima10@gmail.com
}

\section{André Ricardo Fonsêca da Silva}

Doutor em Políticas Públicas e Formação Humana pela Universidade do Estado do Rio de Janeiro (UERJ), Mestre em Ciências Jurídicas pela Universidade Federal da Paraíba (UFPB), Especialista em Direito Municipal pelo Centro Universitário de João Pessoa (UNIPÊ) e Graduado em Direito pela (UNIPÊ).

\begin{abstract}
Resumo
O presente artigo aborda o direito ao esquecimento com ênfase no mundo virtual. Trata-se de instituto relativamente recente, através do qual é discutido o uso dado aos fatos pretéritos passíveis de provocar graves prejuízos aos direitos da personalidade privacidade, intimidade, imagem e honra. Seus preceitos sustentam o direito de ser esquecido em casos específicos, sob certas condições, como a impertinência da informação e seu potencial nocivo, o transcurso do tempo e as circunstâncias atuais. O tema ganhou destaque na atual era informacional após o surgimento da internet e dos mecanismos de busca, principais responsáveis pela eternização da informação. As novas tecnologias vedaram de certa forma o esquecimento, com serviços cujo produto final é a perpetuação dos dados. Com este esforço acadêmico, busca-se debater a viabilidade do direito de ser esquecido, frente as garantias constitucionais de liberdade de imprensa e acesso à informação.
\end{abstract}

Palavras-chave

Direito ao esquecimento; Liberdade de Imprensa; Acesso à informação

\section{Right to oblivion on the internet: consequences of virtual memory}




\begin{abstract}
The present article addresses the right to forgetfulness with an emphasis on the virtual world. It is a relatively recent institute, which discusses the use made of past events that could cause serious damage to the rights of the personality - privacy, intimacy, image and honor. Its precepts uphold the right to be forgotten in specific cases, under certain conditions, such as the impertinence of information and its harmful potential, the passage of time and the present circumstances. The theme gained prominence in the current information era after the emergence of the Internet and search engines, the main responsible for the information eternalization. The new technologies have somehow prevented forgetting, with services whose end product is the perpetuation of data. With this academic effort, we seek to debate the viability of the right to be forgotten, facing the constitutional guarantees of freedom of the press and access to information.
\end{abstract}

\title{
Keywords \\ Right to be forgotten; Freedom of press; Access to information.
}

\section{Sumário}

Introdução; 1 . Origem histórica e direito ao esquecimento; 2 . O direito ao esquecimento no ciberespaço; $2.1 \mathrm{~A}$ informação como capital; 2.2 Direito à privacidade $\mathrm{x}$ Liberdade de imprensa; 3. A efetivação do direito ao esquecimento no ciberespaço; 4. Considerações finais; Referências

\section{Introdução}

O artigo em questão aborda o direito ao esquecimento com ênfase no mundo virtual, criação jurídica relativamente recente, assim como o próprio direito ao esquecimento puro, admitido pelos tribunais brasileiros em meados de 2004. Num primeiro momento, diferencia-se do direito ao esquecimento puro pelo fato de atuar no campo virtual, onde estabelece regras que objetivam a proteção da esfera íntima do cidadão. Com o desenvolvimento da internet e seus reflexos, tornou-se necessário criar novos mecanismos de proteção da personalidade.

Este trabalho propõe a análise do direito ao esquecimento no mundo virtual sob todos os aspectos relevantes, num esforço intelectual intenso a fim de lançar luzes sobre a matéria. É fácil perceber que tal direito deriva do próprio direito ao esquecimento. Mas, afinal, em que ele consiste? Como ainda representa uma novidade no universo jurídico, essa é uma pergunta bastante comum, a que este artigo se dispõe a responder.

Como o próprio nome sugere, consiste em deixar-se absolver pelo esquecimento, de forma a evitar que acontecimentos pretéritos perturbem injustamente o momento atual. Em seu âmago, está o desejo de evitar prejuízos à esfera íntima do cidadão. Através desse 
entendimento, busca-se impedir que fatos irrelevantes e sem valor histórico atrapalhem a vida social do ser humano. Isso porque a eternização da informação, em certos casos, constitui agente capaz de gerar danos gravíssimos.

Um exemplo certamente ajuda a entender melhor o quadro. A doutrina costuma mencionar fatos célebres, como o caso Lebach, na Alemanha, e a Chacina da Candelária, no Brasil. De fato, ambos são bastante esclarecedores e serão examinados no tópico adequado, quando abordada a origem histórica.

O caso de um ex-presidiário ilustra perfeitamente a matéria. Após cumprir pena, procura reinserir-se na sociedade. A cada porta batida, uma oportunidade negada. A pecha de presidiário ainda resiste. Os erros cometidos continuam a ser amplamente noticiados. Apesar de quite com a sociedade, ninguém se arrisca a oferecer oportunidade a um sujeito que aparece na mídia como delinquente. Nesse caso, haveria um direito ao esquecimento? No entender dos defensores dessa tese, sim.

Para os entusiastas da matéria, a vida privada faz jus à tamanha proteção, cuja finalidade principal é evitar que o momento atual seja perturbado por fatos pretéritos, sem nenhuma relevância real em face do modo de vida assumido. Pelo contrário, a lembrança desnecessária apenas causaria transtornos, apesar de totalmente superada do ponto de vista particular. Mas, e quanto ao ponto de vista da sociedade, que certamente ainda cultiva algum preconceito?

O precedente do Superior Tribunal de Justiça (STJ) ao qual a doutrina costuma fazer referência trata do caso da Chacina da Candelária, em que a Egrégia Corte analisou a adoção do direito de ser esquecido pela primeira vez no Brasil. Nessa ocasião, os ministros reconheceram o direito ao esquecimento e condenaram a rede globo de televisão em indenização compensatória a título de danos morais.

Contudo, a matéria tem sido alvo de duras críticas desde o primeiro instante, dada a importância e delicadeza dos bens jurídicos envolvidos. De um lado, o direito ao esquecimento, criação jurídica recente cujo objetivo principal é proteger a esfera íntima do cidadão. Do lado oposto, a liberdade de expressão e acesso à informação, consagradas constitucionalmente pelo ordenamento jurídico brasileiro, que se veem fortemente ameaçadas pelo primeiro. Em meio a um conflito tão gritante, há opiniões em todos os sentidos.

As relações humanas têm cunho bilateral, pois supõem interações entre pelo menos dois sujeitos. Aperfeiçoado com no mínimo dois integrantes, entre os quais são divididos direitos e deveres, o ato jurídico bilateral é caracterizado pela reciprocidade. O termo recíproco significa algo que implica troca ou permuta. Em termos jurídicos, equivale a uma 
relação pautada por direitos e obrigações mútuas, distribuídas entre seus componentes. A cada direito, corresponde uma obrigação.

No caso do direito de ser esquecido, observa-se um elemento extremamente preocupante. Trata-se de sua correspondente obrigação. Como o objetivo central é a obscuridade e o esquecimento, a liberdade de imprensa seria inevitavelmente restringida. Se acolhido o direito de ser esquecido, a mídia seria obrigada a observar certas limitações a fim de respeitá-lo. Alguns conteúdos precisariam ser obrigatoriamente abandonados. 0 problema é que estabelecer limites à imprensa flerta perigosamente com a definição de censura.

Se a aplicação do direito de ser esquecido significa, em certa medida, silenciar a imprensa, é legítimo reconhecê-lo? Sua aplicação caracteriza censura? É possível apagar o passado? Por outro lado, revela-se medida adequada conservar a esfera privada do cidadão desamparada? Os danos causados perante a sociedade merecem ser indenizados? Ao longo desta explanação, o presente artigo buscará responder essas indagações.

Os questionamentos também são recorrentes no âmbito virtual, embora em uma proporção menor, em razão das características identificadoras do ciberespaço - velocidade, atemporalidade e acessibilidade. Sem dúvida alguma, o advento da internet pode ser considerado um grande marco na história dos meios de comunicação, a partir do qual as relações sociais ganharam em velocidade e dinamismo. Com sua criação, várias fronteiras foram rompidas. Agora as publicações virtuais podem ser visualizadas tão logo divulgadas, em qualquer lugar do mundo e durante tempo indefinido.

Um simples erro do passado pode significar perseguição eterna se divulgado na internet. Após publicado, é possível acessá-lo com apenas um click, seja um ano ou uma década depois. Os mecanismos de busca - Google, Bing, Yahoo - proporcionam acesso a milhões de informações, com esforço mínimo e sem qualquer dificuldade. Imagine uma informação desabonadora a seu respeito na internet. Ao pesquisar seu nome no Google, o primeiro resultado é exatamente o dado constrangedor. Cinco anos depois, nada mudou. Continua a ser julgado e condenado pelos erros do passado, em função do acesso recorrente ao fato comprometedor. Seria razoável um direito ao esquecimento em casos semelhantes?

A internet apenas evidenciou definitivamente o problema, cuja origem remonta aos meios de comunicação clássicos, como jornais e televisões. Além de oferecer um espaço livre para circulação de ideias, o que é extremamente positivo, eterniza e facilita a busca pelas informações, ponto negativo a ser analisado. Uma vez dentro da rede virtual, nada 
jamais será esquecido, devido à facilidade oferecida pelos mecanismos de busca, ainda que motivo de dor e sofrimento.

No Brasil, já existem proposições legislativas sobre o assunto, ainda que de forma incipiente. Ao abordá-lo, o Congresso Nacional procura atender a uma demanda social, uma vez que casos semelhantes têm desembocado no Judiciário brasileiro. Prejudicados pela eternização das notícias, a procura pela via judicial vem sendo cada vez mais frequente, como única maneira capaz de solucionar a questão.

A presente investigação foi norteada pelo método dedutivo, pois tomou como parâmetro uma premissa universal, o direito ao esquecimento, para alcançar uma premissa particular, o direito ao esquecimento na internet. Da mesma forma, utilizou-se da técnica de revisão bibliográfica, pois o conhecimento necessário para discorrer a respeito do tema deriva de profunda pesquisa acadêmica.

Este artigo está dividido em dois tópicos principais, além da introdução e considerações finais. O primeiro aborda a origem histórica do direito ao esquecimento, onde são analisados precedentes importantes para compreensão da matéria. O segundo trata do direito ao esquecimento no ciberespaço e suas implicações, desde o exame da informação como capital até a efetivação do instituto ora em análise na internet.

\section{Origem histórica do direito ao esquecimento}

O direito ao esquecimento surgiu inicialmente no direito penal, como elemento essencial à ressocialização dos presos. Os estudiosos do direito constataram a importância do instituto ao analisarem a reintegração social dos ex-presidiários. A ideia de ser perseguido eternamente pelos erros do passado revelou-se desarrazoada. Parece no mínimo incoerente pretender a ressocialização sem oferecer os meios necessários para tanto. Daí as primeiras noções de direito ao esquecimento, aplicado com a finalidade de proporcionar as condições necessárias à ressocialização do preso.

No Brasil, o direito ao esquecimento é relativamente recente. A tese foi discutida pela primeira vez nos tribunais brasileiros em 2004, numa sessão do STJ, onde a Egrégia Corte reconheceu de maneira inédita o direito de ser esquecido. A decisão alcançou grande repercussão no meio jurídico e gerou inúmeras polêmicas envolvendo defensores e críticos da medida.

O STJ julgou dois casos semelhantes, em que ambos os autores pretendiam o direito de ser esquecido. Todos dois movidos contra a rede globo de televisão, acusada de ferir a honra, imagem, privacidade e dignidade dos demandantes, ao exibir indevidamente os 
casos em rede nacional. Para os autores da ação, a veiculação dos episódios, depois de esquecidos pelo público geral, abalou a honra dos personagens envolvidos, que desejavam apenas o conforto da obscuridade.

O primeiro caso ficou conhecido pela imprensa como Chacina da Candelária (Acórdão do REsp 1.334.097 - RJ). O crime provocou comoção nacional pela crueldade com que foi praticado. Cerca de vinte anos atrás, policiais à paisana alvejaram sumariamente enquanto dormiam, na calçada da Igreja da Candelária, aproximadamente 60 crianças. Ao retratar o episódio quase uma década depois, a rede globo de televisão identificou claramente Jurandir França, indiciado e inocentado pela justiça.

Depois da exibição do programa em rede nacional, antigos males voltaram a assombrar Jurandir, como a revolta popular em torno de sua figura, associada a um crime bárbaro, apesar de inocentado pelo Poder Judiciário. A transmissão teria abalado o cotidiano do autor, gerando prejuízos sociais e profissionais. O STJ entendeu que a identificação ofendeu o direito de ser esquecido e condenou a demandada ao pagamento de uma indenização.

O segundo exemplo, julgado na mesma ocasião, refere-se ao caso de Aída Curi (Recurso Especial n. 1.335.153-RJ). Não se sabe exatamente as circunstâncias em que o crime ocorreu; existem apenas suposições, baseadas nos indícios deixados na cena do crime. O episódio chocou o Brasil inteiro, que se comoveu com a trágica e humilde história de Aída Curi, jovem simples e extremamente devota. Sabe-se apenas que foi atacada por um grupo de arruaceiros e acabou arremessada do terraço de um prédio.

Muitos anos depois, ao reeditar a narrativa no programa Linha Direta, a rede globo identificou claramente a figura de Aída Curi, através de fotos e simulações. Os familiares da vítima procuraram o Judiciário, alegando que tamanha exposição reavivara toda a dor e aflição experimentadas na época. O STJ acolheu a tese e reconheceu o direito ao esquecimento concernente aos seus parentes. Contudo, como o episódio ganhara notabilidade como Caso Aída Curi, admitiu ser inviável recontar a história sem fazer alusão à vítima. Concluiu que, desde que fosse identificada sem nenhum viés sensacionalista, nenhuma indenização seria devida.

Gilmar Ferreira Mendes e Paulo Gustavo Gonet Branco, discorrendo sobre o direito à privacidade, observam o seguinte:

A celebridade do passado nem sempre será objetivo legítimo de incursões da imprensa. Algumas pessoas de renome voltam, adiante, espontaneamente, ao recolhimento da vida de cidadão comum -

Revista Publicum

Rio de Janeiro, v.2, n. 2, 2016, p. 324-346

http://www.e-publicacoes.uerj.br/index.php/publicum

DOI: $10.12957 /$ publicum.2016.25983 
opção que deve ser, em princípio, respeitada pelos órgãos de informação. Se a pessoa deixou de atrair notoriedade, desaparecendo o interesse público em torno dela, merece ser deixada de lado, como desejar. Isso é tanto mais verdade com relação, por exemplo, a quem já cumpriu pena criminal e que precisa reajustar-se à sociedade. Ele há de ter o direito a não ver repassados ao público os fatos que o levaram à penitenciária. (MENDES; BRANCO, 2012, p.353).

No plano internacional, a doutrina costuma fazer referência ao caso Lebach, como um dos precursores do direito ao esquecimento. A fatalidade ocorreu na Alemanha, onde quatro soldados da guarda sentinela de um depósito Alemão, perto da cidade de Lebach, foram cruelmente assassinados enquanto dormiam. Logo em seguida, os homicidas roubaram as armas vigiadas pelos soldados, com as quais pretendiam alastrar o terror pela cidade. Alguns anos depois, quando o episódio havia sumido quase por completo da memória popular, uma rede de televisão alemã planejava exibir um documentário a respeito, cujo título era "O assassinato de soldados em Lebach".

Após duas derrotas em instâncias inferiores, um dos condenados como cúmplice no caso, prestes a concluir a pena e readquirir a liberdade, conseguiu no Tribunal Constitucional Alemão impedir a exibição do documentário. O tribunal atendeu ao pedido do autor, para quem a veiculação do documentário, em que era nominalmente citado e identificado através de fotos, prejudicaria a devida ressocialização.

Em termos de direito ao esquecimento na web, objeto principal deste esforço acadêmico, existe um marco jurisprudencial importantíssimo, cujos efeitos inspiraram várias decisões semelhantes pelos tribunais mundo afora. Trata-se de uma decisão do Tribunal de Justiça da União Europeia (TJUE), em que esta ilustre Corte declarou procedente ação movida contra o Google, principal servidor de busca mundial. Por esse acordão, o TJUE reconheceu o direito de ser esquecido na internet, sob certas condições.

O caso em questão refere-se a um cidadão espanhol, insatisfeito com os resultados apresentados pelo Google, ao pesquisar seu perfil no mecanismo de busca. A ferramenta exibia uma série de informações, entre as quais constava um leilão judicial de imóveis de 1998, em que figurava como executado, devido ao inadimplemento de uma dívida. O link apresentado remetia à matéria de um jornal, em que era possível concluir pela pecha de velhaco. O autor considerou a associação ofensiva e capaz de gerar graves prejuízo sociais. 
Como decorrência do direito de ser esquecido, o tribunal determinou a remoção do link pelo Google, considerado irrelevante do ponto de vista atual, uma vez que a dívida fora adimplida e o imbróglio judicial solucionado.

Os links para sites que contêm esta informação devem ser suprimidos da lista de resultados, a menos que existam razões particulares - como o papel desempenhado por esta pessoa na vida pública - que justifiquem que prevaleça o interesse do público a ter acesso a esta informação ao efetuar a busca. (TRIBUNAL DE JUSTIÇA DA UNIÃO EUROPEIA, 2014).

Em artigo publicado na revista novos estudos jurídicos, João dos Passos Martins Neto e Denise Pinheiro definem o direito ao esquecimento como:

A partir do observado na doutrina e no precedente do STJ, é possivel concluir que o direito ao esquecimento é concebido, em suma, como o direito de não ser citado no corpo de um relato atual sobre fatos pretéritos de caráter público; é o direito de não ser lembrado, de não ter uma passagem ruim da vida recontada agora, tantos anos depois, apesar da sua veracidade e desde que a evocação da história se mostre nociva à vida da pessoa implicada. (PASSOS NETO; PINHEIRO, 2014, p. 822).

Viktor Mayer Schönberger, professor da Universidade de Oxford e autor do livro Delete: The Virtues of Forgetting in the Digital Age (Apagar: As Virtudes de Esquecer na Era Digital), defende a necessidade de um direito ao esquecimento:

Enquanto nós mesmos estamos esquecendo e reconstruindo elementos do nosso passado, as outras pessoas, usando a lembrança digital, podem acessar fatos que não foram reconstruidos, que estão congelados no tempo. Provavelmente essas duas visões irão se chocar - a memória congelada que os outros têm de nós, e a nossa memória, que evolui nas nossas mentes. (SCHÖNBERGER, 2011, p. 115, tradução nossa). 
O Conselho da Justiça Federal (CJF) assumiu posição similar, na VI Jornada de Direito Civil, quando lançou o enunciado no 531, conforme o qual "a tutela da dignidade da pessoa humana na sociedade da informação inclui o direito ao esquecimento". (SUPERIOR TRIBUNAL DE JUSTIÇA, 2013).

Esta afirmação indica a necessidade de um direito ao esquecimento, sobretudo na atual era informacional, a qual o enunciado no 531 fez questão de mencionar em função de sua importância. Como elemento de pacificação social, o direito deve se voltar às novas questões jurídicas, principalmente numa época em que a privacidade do cidadão está cada vez mais vulnerável.

\section{O direito ao esquecimento no ciberespaço}

Segundo o Conselho da Justiça Federal (CFJ), durante a VI Jornada de Direito Civil, na justificativa do Enunciado no 531, os avanços tecnológicos são responsáveis por novas questões, ligadas ao modo como os juristas vêm lidando com as informações desde o desenvolvimento da web. As relações virtuais apresentam características singulares e devem ser consideradas pelos operadores do direito. Somente assim terão condições de responder satisfatoriamente aos novos dilemas. Nesse sentido, é imprescindível observar o contexto em que o direito ao esquecimento se insere no universo virtual.

Como define Pierre Lévy (1999, p.17), especialista na área, o ciberespaço consiste no lugar onde as relações virtuais se desenvolvem, sob os efeitos da cultura virtual. Apresenta características extremamente peculiares, com as quais os juristas estão despreparados para lidar, mas que precisam ser respeitadas. Alguns institutos devem se adaptar ao espaço onde pretendem adentrar, a exemplo do direito ao esquecimento. Transferir simplesmente a lógica comum para o universo virtual apenas incentivaria a ineficácia da norma.

Em relação à figura jurídica ora analisada, três características do ciberespaço revelam-se importantíssimas, reforçando a necessidade do direito de ser esquecido na era informacional. Se levadas em consideração, a ausência de proteção jurídica representa um prejuízo gigantesco, uma vez que funcionam como elementos intensificadores da eternização das informações, em qualquer área do direito - Civil, Penal e etc. Trata-se da velocidade, atemporalidade e acessibilidade.

Quanto à primeira característica, é inegável que as relações sociais mudaram profundamente após o surgimento da internet, ostentando uma velocidade tamanha que fazem jus à alcunha de instantâneas. No âmbito virtual, as informações se propagam de 
maneira alucinante, numa interação imediata entre autor e receptor da mensagem. Sem dúvida alguma, a web consiste em um meio de comunicação extremamente democrático e acessível. Apresenta-se como um espaço livre, onde qualquer um pode produzir seu próprio conteúdo e disponibilizá-lo para quem bem entender. Ao que o público alvo responde imediatamente, interagindo e reproduzindo o material ou apenas ignorando. O fluxo diário de dados e a velocidade das interações são assustadoras. Em artigo a respeito, observa Elisângela Campos:

A gigantesca quantidade de novas notícias, textos, vídeos e músicas disponibilizados em sites, blogs, fóruns de discussão e redes sociais diariamente não são a única característica distintiva da Internet em relação aos outros meios de comunicação de massa. A disponibilidade imediata e global dessas produções humanas é a marca que diferencia a Internet dos demais meios de comunicação, seus antecessores. Vivemos em um espaço global, onde "qualquer ponto pode ser exposto imediatamente à totalidade" (INNERARITY, 2006, p. 260). (SOARES, 2014, p. 2).

Outra característica realmente importante é a atemporalidade, instituída pela internet e pelos mecanismos de busca, cuja praticidade permite a eternização dos dados. Com uma simples pesquisa, é possível acessar uma fonte quase inesgotável de dados, desde informações alusivas aos primórdios da internet até notícias extremamente atuais. Uma vez lançados na internet, jamais serão esquecidos, visto que podem ser acessados a qualquer momento. Nem erros, nem acertos são relevados. É como se a rede mundial de computadores impedisse o esquecimento, funcionando como uma espécie de memória auxiliar, sempre à disposição para reparar eventuais falhas.

Antes de a internet assumir um papel importantíssimo entre os meios de comunicação, a memória social era extremamente frágil, se comparada à existente atualmente. Ninguém era obrigado a conviver eternamente com as próprias mancadas, porque desapareciam naturalmente da memória coletiva. Ao contrário do que se vê no mundo virtual, onde o estigma permanece vivo e acessível. Em vez de esquecido, o autor é novamente condenado pelas falhas cometidas, devido ao acesso recorrente ao dado comprometedor. Para evoluir como sociedade, é preciso olvidar certas falhas, coisa que a internet nega ao relembrar frequentemente fatos pretéritos, embaraçando a reconstrução da vida do envolvido. Elisângela Campos ressalta:

Revista Publicum

Rio de Janeiro, v.2, n. 2, 2016, p. 324-346

http://www.e-publicacoes.uerj.br/index.php/publicum

DOI: $10.12957 /$ publicum.2016.25983 
Nessa era da informação onipresente, já não há memória que se esconda - sigilosa é apenas a memória nunca revelada. Diz-se que o sigilo processual é um refúgio da memória, salvaguardada pela couraça judiciária, que a isola do conhecimento público. Mas até mesmo os processos judiciais passam pelo processo de digitalização, $e$ se um dia esse sigilo for quebrado, tanto pelo tempo decadencial quanto por expressa liberação do juiz, seu acesso será muito facilitado pelas próprias características do processo digital, que permite $o$ trânsito rápido de "pilhas e pilhas" de informações. Além do mais, há sempre o risco da insegurança informática, seja por falhas técnicas, seja pelo ataque de hackers, o que pode expor informações sigilosas a pessoas mal-intencionadas. (SOARES, 2014, p. 2).

No meio virtual, até situações tolas, que em circunstâncias normais seriam desconsideradas, podem provocar danos sérios. Os jovens da atual geração são os primeiros a crescer sob os efeitos da cultura virtual. Provavelmente incorrerão em algum ato inconsequente até atingir a fase adulta. Ao alcançar a maturidade, já terão feito alguma coisa de que se arrependam - atitudes irresponsáveis, opiniões radicais, embriaguez ao volante e outras. Se registradas sob a forma de fotos ou vídeos e jogadas na internet, serão obrigados a lidar com implicações futuras. Seus comportamentos adolescentes serão avaliados sob o ponto de vista adulto, visto que os mecanismos de busca impedem o esquecimento. Em alguns casos, as consequências podem ser drásticas: estigmas, perseguição social, bullying, dificuldades para encontrar emprego etc.

Já em relação à última característica - a acessibilidade seus efeitos são evidentes. Como já afirmado insistentemente, a internet facilitou significativamente a pesquisa bibliográfica, que exigia um esforço tremendo em vários sentidos. Às vezes era necessário percorrer grandes distância e realizar uma pesquisa minuciosa em acervos gigantescos. Após o advento da web, as dificuldades diminuíram, com a digitalização de bibliotecas inteiras, bancos de dados de jornais e informações em geral. As barreiras geográficas foram rompidas. Antes resultado de um processo extremamente custoso, as pesquisas agora dependem apenas de um clique, graças a tendência generalizada de digitalização.

Contudo, tamanha facilidade tem um lado dramático em matéria de direito ao esquecimento, comprometido pelas características identificadoras do ciberespaço: velocidade, atemporalidade e acessibilidade. Em um meio em que as informações se 
disseminam numa velocidade assustadora, durante tempo indefinido e permanecem extremamente acessíveis, o direito de ser esquecido deve ser fortalecido. Se algum dado comprometedor cair na rede virtual, o cidadão perde completamente o controle sobre ele. Seu conteúdo pode ser revisitado a qualquer instante, fazendo o dano renascer. $\mathrm{Na}$ verdade, a única coisa esquecida é o direito à privacidade e intimidade. A revista Galileu cita um exemplo esclarecedor.

Em 2009, uma professora baiana resolveu (sob efeito do álcool, ela disse depois) dançar no palco de um show de pagode. A música chamava Todo Enfiado, e a coreografia envolvia, entre outras coisas, levantar a saia e rebolar na direção do público. O vídeo da performance foi parar no YouTube e a professora foi identificada, perseguida em seu bairro e demitida da escola onde recebia um salário de menos de $R S$ 1.000. Já desempregada, ela ainda tentou tirar o vídeo do ar por meio de um processo judicial, mas isso também não funcionou. Depois, sem muitas opções, restou seguir carreira como dançarina. Ainda hoje, uma busca pelo seu nome completo no Google traz o vídeo polêmico como primeiro resultado. (BURGOS, 2014).

O direito ao esquecimento se concretiza com a devida exclusão dos links dos mecanismos de busca. Para evitar eventuais alegações de censura, a remoção limita-se aos links, responsáveis por promover o acesso fácil as informações comprometedoras. Com isso, objetiva-se a proteção do direito à privacidade, intimidade, imagem e honra, consagrados constitucionalmente como direitos fundamentais. A desindexação dos links, por sua vez, deve observar critérios claros. Somente as informações ofensivas e irrelevantes merecem sumir dos resultados de busca. Mas como realizar essa distinção? Talvez esse seja o grande desafio do direito ao esquecimento.

\subsection{A informação como capital}

A adoção do capitalismo pela grande maioria dos países desenvolvidos resultou em vários avanços, pelo menos em matéria de tecnologia, entendida como responsável pelo crescimento vivenciado por muitos deles. A livre concorrência fez bem à criatividade humana, já que tudo gira em torno do lucro e boas invenções significam montanhas de dinheiro. Os estímulos certamente são torpes, mas os resultados alcançados são surpreendentes. O capitalismo exerceu um papel importantíssimo no desenvolvimento 
tecnológico experimentado pelas grandes potências mundiais, onde a concorrência é livre e o estado intervém o mínimo possível na economia. Os ideais liberais aparentemente prevaleceram sobre os princípios socialistas. Seguindo a tendência mundial, a busca incessante pelo lucro chegou ao universo das informações, do processamento e armazenamento de dados.

Milhões de usuários navegam diariamente pela internet e deixam um rastro de informações gigantesco, cuja importância até pouco tempo era nula. Mas isso mudou. Com a criação do Big Data, as informações geradas pelos milhões de usuários ganharam uma destinação útil, a fim de fazer a roda da economia girar. Os grandes investidores em Tecnologia da Informação (TI) aprenderam a decifrar cada indício deixado na rede virtual. Descobriram o que cada um significa e como podem ser usados economicamente. $O$ comportamento do consumidor se tornou de certa forma previsível, graças ao lastro deixado pelos internautas, interpretado minuciosamente pelos analistas de dados virtuais. Os hábitos dos consumidores na internet - preferências, pesquisas, conteúdos compartilhados, fotos, sites visitados etc. - revelam bastante sobre suas identidades. Em termos objetivos, observa-se as informações particulares dos usuários a serviço do capitalismo. Carolina Cunha, por sua vez, salienta:

As informações podem ser as mais variadas possíveis, desde hábitos de consumo, a reação a produtos. A análise desses dados ajuda empresários a definir estratégias, mapear mercados, enxergar tendências, reduzir custos, nortear inovações e melhorar o relacionamento com clientes. (CUNHA, 2015).

O jornal Folha de São Paulo, em reportagem a respeito do assunto, conceitua o Big Data como "um termo utilizado para descrever o conjunto de soluções tecnológicas ou uma ciência feita a partir das megabases de dados disponíveis na internet, que analisam e dão sentido a essas informações". (OLIVEIRA, 2015).

Assim como quase tudo no sistema capitalista, as informações são dispostas e analisadas de maneira a otimizar o lucro. Podem inclusive melhorar a qualidade de certos serviços, ajudando-os a ser mais eficientes. Mas e quanto ao direito de ser esquecido? Como objetiva o esquecimento do cidadão, pela remoção de links considerados obsoletos dos mecanismos de buscas, é visto como uma ameaça à economia capitalista. Certamente uma ameaça pequena, mas cada centavo é importante num sistema onde a lei maior é a busca pelo lucro. Para os exploradores das novas técnicas de análise de dados, se as 
informações fossem retiradas da internet, e a eliminação criasse uma tendência, o acervo de dados disponíveis diminuiria significativamente. Sistemas baseados na análise detalhada de indícios virtuais perderiam parte de seu potencial e os lucros obtidos diminuiriam. 0 segredo dos serviços oferecidos pelas ferramentas de busca está na quantidade gigantesca de informações oferecidas. Quanto mais, melhor. A redução da quantidade certamente comprometeria a capacidade de atrair usuários. Adverte Carolina Cunha:

Com o cruzamento de informações, empresas e instituições buscam capturar, armazenar e analisar uma série de dados para apoiar decisões estratégicas, inovar e entender melhor o comportamento do consumidor ou de um determinado público ou ainda para identificar tendências de eventos de vida e oferecer um produto com antecedência, como um casal que vai se casar e recebe uma oferta para comprar um apartamento. (CUNHA, 2015).

Como representa uma ameaça ao faturamento capitalista, o direito ao esquecimento enfrenta resistência no meio virtual, capitaneada pelos mecanismos de busca e por empresas especializadas na análise de dados virtuais. É de se esperar que um eventual pedido de remoção de link seja negado, como geralmente acontece. A Europa é uma das poucas regiões onde isso não costuma ocorrer, visto que o Tribunal de Justiça da União Europeia acolheu a tese do direito ao esquecimento. Apesar da pressão exercida pelos setores interessados, a referida Corte Superior reconheceu o direito de ser esquecido como fundamental para proteção da privacidade na era informacional. Quando os empreendedores descobriram a possibilidade de utilizar os dados dos usuários na otimização dos lucros, relegaram a segundo plano o direito à privacidade. Este passou a ser visto como uma espécie de empecilho, contra o qual é necessário lutar, para restringir ao máximo as chances de perdas. Tudo porque sistemas de análise de dados como o Big Data dependem de um banco gigantesco de informações. Nas palavras de Carolina Cunha:

A Internet criou um contexto em que as questões de privacidade precisam ser repensadas. Se por um lado acessar informações públicas ficou mais fácil, a coleta de informações particulares, sem autorização dos indivíduos, também se tornou mais frequente. E para conter este segundo avanço, marcos, leis e normas precisam ser criadas para atender ao que acontece no ciberespaço. (CUNHA, 2015).

Revista Publicum

Rio de Janeiro, v.2, n. 2, 2016, p. 324-346

http://www.e-publicacoes.uerj.br/index.php/publicum

DOI: 10.12957/publicum.2016.25983 
Portanto, é forçoso admitir que, na atual era informacional, em que o homem está sujeito a milhares de ingerências em sua vida privada, o direito ao esquecimento vem se firmando como instrumento jurídico indispensável à proteção dos direitos da personalidade.

\subsection{Direito à privacidade $x$ Liberdade de imprensa}

A adoção do capitalismo pela grande maioria dos países desenvolvidos resultou em vários avanços, pelo menos em matéria de tecnologia, entendida como responsável pelo crescimento vivenciado por muitos deles. A livre concorrência fez bem à criatividade humana, já que tudo gira em torno do lucro e boas invenções significam montanhas de dinheiro. Os estímulos certamente são torpes, mas os resultados alcançados são surpreendentes. O capitalismo exerceu um papel importantíssimo no desenvolvimento tecnológico experimentado pelas grandes potências mundiais, onde a concorrência é livre e o Estado intervém o mínimo possível na economia. Os ideais liberais aparentemente prevaleceram sobre os princípios socialistas. Seguindo a tendência mundial, a busca incessante pelo lucro chegou ao universo das informações, do processamento e armazenamento de dados.

Milhões de usuários navegam diariamente pela internet e deixam um rastro de informações gigantesco, cuja importância até pouco tempo era nula. Mas isso mudou. Com a criação do Big Data, as informações geradas pelos milhões de usuários ganharam uma destinação útil, a fim de fazer a roda da economia girar. Os grandes investidores em Tecnologia da Informação (TI) aprenderam a decifrar cada indício deixado na rede virtual. Descobriram o que cada um significa e como podem ser usados economicamente. 0 comportamento do consumidor se tornou de certa forma previsível, graças ao lastro deixado pelos internautas, interpretado minuciosamente pelos analistas de dados virtuais. Os hábitos dos consumidores na internet - preferências, pesquisas, conteúdos compartilhados, fotos, sites visitados e etc. - revelam bastante sobre suas identidades. Em termos objetivos, observa-se as informações particulares dos usuários a serviço do capitalismo. Carolina Cunha, por sua vez, salienta:

As informações podem ser as mais variadas possíveis, desde hábitos de consumo, a reação a produtos. A análise desses dados ajuda empresários a definir estratégias, mapear mercados, enxergar 
tendências, reduzir custos, nortear inovações e melhorar o relacionamento com clientes. (CUNHA, 2015).

O jornal Folha de São Paulo, em reportagem a respeito do assunto, conceitua o Big Data como "um termo utilizado para descrever o conjunto de soluções tecnológicas ou uma ciência feita a partir das megabases de dados disponíveis na internet, que analisam e dão sentido a essas informações". (OLIVEIRA, 2015).

Assim como quase tudo no sistema capitalista, as informações são dispostas e analisadas de maneira a otimizar o lucro. Podem inclusive melhorar a qualidade de certos serviços, ajudando-os a ser mais eficientes. Mas e quanto ao direito de ser esquecido? Como objetiva o esquecimento do cidadão, pela remoção de links considerados obsoletos dos mecanismos de buscas, é visto como uma ameaça à economia capitalista. Certamente uma ameaça pequena, mas cada centavo é importante num sistema onde a lei maior é a busca pelo lucro. Para os exploradores das novas técnicas de análise de dados, se as informações fossem retiradas da internet, e a eliminação criasse uma tendência, o acervo de dados disponíveis diminuiria significativamente. Sistemas baseados na análise detalhada de indícios virtuais perderiam parte de seu potencial e os lucros obtidos diminuiriam. 0 segredo dos serviços oferecidos pelas ferramentas de busca está na quantidade gigantesca de informações oferecidas. Quanto mais, melhor. A redução da quantidade certamente comprometeria a capacidade de atrair usuários. Adverte Carolina Cunha:

Com o cruzamento de informações, empresas e instituições buscam capturar, armazenar e analisar uma série de dados para apoiar decisões estratégicas, inovar e entender melhor o comportamento do consumidor ou de um determinado público ou ainda para identificar tendências de eventos de vida e oferecer um produto com antecedência, como um casal que vai se casar e recebe uma oferta para comprar um apartamento. (CUNHA, 2015).

Como representa uma ameaça ao faturamento capitalista, o direito ao esquecimento enfrenta resistência no meio virtual, capitaneada pelos mecanismos de busca e por empresas especializadas na análise de dados virtuais. É de se esperar que um eventual pedido de remoção de link seja negado, como geralmente acontece. A Europa é uma das poucas regiões onde isso não costuma ocorrer, visto que o Tribunal de Justiça da União Europeia acolheu a tese do direito ao esquecimento. Apesar da pressão exercida

Revista Publicum

Rio de Janeiro, v.2, n. 2, 2016, p. 324-346

http://www.e-publicacoes.uerj.br/index.php/publicum

DOI: $10.12957 /$ publicum.2016.25983 
pelos setores interessados, a referida Corte Superior reconheceu o direito de ser esquecido como fundamental para proteção da privacidade na era informacional. Quando os empreendedores descobriram a possibilidade de utilizar os dados dos usuários na otimização dos lucros, relegaram a segundo plano o direito à privacidade. Este passou a ser visto como uma espécie de empecilho, contra o qual é necessário lutar, para restringir ao máximo as chances de perdas. Tudo porque sistemas de análise de dados como o Big Data dependem de um banco gigantesco de informações. Nas palavras de Carolina Cunha:

A Internet criou um contexto em que as questões de privacidade precisam ser repensadas. Se por um lado acessar informações públicas ficou mais fácil, a coleta de informações particulares, sem autorização dos indivíduos, também se tornou mais frequente. E para conter este segundo avanço, marcos, leis e normas precisam ser criadas para atender ao que acontece no ciberespaço. (CUNHA, 2015).

Portanto, é forçoso admitir que, na atual era informacional, em que o homem está sujeito a milhares de ingerências em sua vida privada, o direito ao esquecimento vem se firmando como instrumento jurídico indispensável à proteção dos direitos da personalidade.

\section{A efetivação do direito ao esquecimento no ciberespaço}

O conceito de direito ao esquecimento sugere certa placidez social e interior, com a qual o indivíduo consiga reconstruir sua vida, sem sofrer qualquer espécie de perseguição, especialmente ligada a fatos pretéritos. A professora Marion Albers (2015, p.30), titular da Faculdade de Direito da Universidade de Hamburgo, classifica o direito de ser esquecido na internet como "uma reação ao desenvolvimento tecnológico" e ressalta sua necessidade numa época em que "tudo que era facilmente esquecido ou não tão transmitido, hoje é mais difícil de ser esquecido". A internet é um espaço atemporal, onde qualquer informação pode ser pesquisada a qualquer momento, inclusive fatos antigos e indesejáveis. Essa facilidade muitas vezes perturba injustamente o momento atual.

Motivados pelas demandas sociais oriundas do meio virtual, o Tribunal de Justiça da União Europeia proferiu decisão inédita, cujos efeitos repercutiram pelo mundo inteiro. Trata-se do primeiro precedente acerca da questão, pelo qual o Tribunal Europeu 
"reconheceu o direito ao esquecimento de um cidadão espanhol e obrigou o Google a eliminar de seu mecanismo de busca qualquer resultado que o ligasse a dívidas à segurança social”. (SARLET, 2015, p. 30). Quando pesquisava seu nome no servidor de busca, o processo de execução gerado pela dívida aparecia como primeiro resultado. O fato havia ocorrido muitos anos antes e o cidadão espanhol se sentiu prejudicado pela matéria, na qual era possível deduzir a pecha de caloteiro.

A decisão da ilustre Corte Europeia considerou os mecanismos de busca responsáveis pelos dados armazenados, cabendo-Ihes excluir eventuais links ligados a informações ofensivas ao direito de ser esquecido, algo que ocorre quando a lembrança de fatos pretéritos prejudica o momento atual. Além de ressaltar a circunstância de que a tese vale apenas quando os "dados são considerados inadequados, não pertinentes ou não mais pertinentes do ponto de vista dos fins para os quais foram tratados e do tempo transcorrido". (TRIBUNAL DE JUSTIÇA DA UNIÃO EUROPEIA, 2014).

No Brasil, a tese do direito ao esquecimento vem sendo bem recebida pelos tribunais, sob o argumento de que os direitos da personalidade constituem limite a liberdade de imprensa, a exemplo do direito à privacidade, imagem e honra. Como a matéria ainda precisa ser disciplinada pelo Poder Legislativo, as decisões são inspiradas em entendimentos jurisprudenciais, que buscam responder a demanda crescente da sociedade. O aumento da procura pelo Judiciário é explicado pelas características da internet, na qual a eternização da informação encontra ambiente propício.

Instada a analisar a matéria, a Quarta Câmara Cível do Tribunal de Justiça da Bahia decidiu da seguinte forma:

A irresignação da ré não merece amparo, pois esbarra justamente no direito ao esquecimento que pertence a todo cidadão, vez que serviços indexadores de busca realizam na verdade um efeito multiplicador, tornando o alcance global e eterno. Registre-se que não se trata de suprimir direitos consagrados como o da comunicação ou da informação, como já decidiu o Egrégio STJ. (TRIBUNAL DE JUSTIÇA DA BAHIA, 2013).

Pelo entendimento da Corte Europeia, o direito de ser esquecido na internet se concretiza através da eliminação dos links dos servidores de busca. O site em que a informação está hospedada permanece intacto. Qualquer interessado poderá acessá-lo diretamente. Portanto, a alegação de censura no meio virtual é infundada. A informação 
original sequer é afetada. Possíveis pesquisadores poderão acessar diretamente a matéria, sem o auxílio dos mecanismos de busca, considerados como principal responsável pela eternização da informação invasiva.

A eliminação de links, como consequência do direito ao esquecimento, deve ser baseada em critérios claros e rigorosos. A exclusão arbitrária caracterizaria censura, sob o pretexto de respeito à privacidade, fundamento principal do esquecimento. Como visto anteriormente, o ordenamento jurídico brasileiro refuta a censura prévia. A importância da liberdade de imprensa numa sociedade democrática é evidente. O nível de esclarecimento dos cidadãos depende do pensamento livre. Apesar da relevância, é um direito fundamental como qualquer outro e deve respeitar os demais. Assim, o exercício da liberdade de imprensa deve observar a dignidade humana como limite fundamental.

O link sempre remete a uma informação - notícia, matéria, especulação. Ele só deve ser excluído do servidor de busca se seu conteúdo ofender os valores inerentes a dignidade humana. O esquecimento é uma alternativa excepcional, uma vez que funciona como regulador dos danos causados pela eternização da informação. Para ser removido, além de afetar os direitos da personalidade, há de ser completamente irrelevante do ponto de vista atual. Se possuir alguma importância, seja pública ou histórica, merece ser protegido pelo manto da liberdade de imprensa, devido ao seu valor para as futuras gerações.

O Conselho da Justiça Federal compartilha do entendimento supramencionado, consignado nos dizeres "a tutela da dignidade da pessoa humana na sociedade da informação inclui o direito ao esquecimento" do Enunciado no 531 da VI Jornada de Direito Civil, cuja justificativa assevera:

Os danos provocados pelas novas tecnologias de informação vêm-se acumulando nos dias atuais. O direito ao esquecimento tem sua origem histórica no campo das condenações criminais. Surge como parcela importante do direito do ex-detento à ressocialização. Não atribui a ninguém o direito de apagar fatos ou reescrever a própria história, mas apenas assegura a possibilidade de discutir o uso que é dado aos fatos pretéritos, mais especificamente o modo e a finalidade com que são lembrados. (SUPERIOR TRIBUNAL DE JUSTIÇA, 2013).

Por conseguinte, a aplicação do direito ao esquecimento no ciberespaço é perfeitamente possível, apesar das alegações de censura de alguns grupos, para quem a liberdade de imprensa é absoluta e irrestrita. A Constituição afirma exatamente o contrário, 
visto que reconhece a importância dos direitos da personalidade, sem os quais a dignidade da pessoa humana estaria completamente à deriva. Numa sociedade tão tumultuada quanto a atual, resguardar a privacidade do indivíduo é essencial para um desenvolvimento mental saudável. Conservar um espaço onde o homem se sinta à vontade e livre da opressão social. Como afirmado na justificativa do Enunciado no 531, ninguém pretende reescrever a própria história, mas garantir o direito de discutir o uso que é dado aos fatos pretéritos.

\section{Considerações Finais}

O presente trabalho procurou destrinchar o direito ao esquecimento em todos os aspectos, com ênfase no âmbito virtual, em que a sua aplicação ganhou destaque após decisão inédita do Tribunal de Justiça da União Europeia. Buscou também apontar os desafios apresentados a referida tese para se firmar como instrumento jurídico indispensável na atual era informacional, a exemplo do embate já conhecido entre privacidade e liberdade de imprensa. Urge superar as restrições feitas a sua implementação, especialmente em relação ao risco de censura e destruição do patrimônio histórico.

No espaço criado pela web, nasceu a chamada cultura virtual, sobre a qual o direito precisa se debruçar. Assim como a sociedade, o direito é uma ciência dinâmica, que muda e se adequa as mutações sociais. A internet, por sua vez, representa uma grande mudança, da qual é impossível escapar. Como o ciberespaço apresenta novas situações, é necessário discipliná-las. É o caso do direito ao esquecimento no mundo virtual.

No primeiro tópico, em que a origem histórica do instituto foi estudada, é possível observar tratar-se de tese amplamente discutida, tanto no âmbito nacional quanto internacional, baseada principalmente na proteção da vida privada do indivíduo. Sem sombra de dúvidas, o uso abusivo de fatos pretéritos pode gerar graves prejuízos à intimidade, especialmente quando o objeto da publicação impede o envolvido de retomar sua vida. Em menor ou maior escala, o direito de ser esquecido vem sendo adotado no mundo inteiro, como medida essencial para neutralizar os efeitos colaterais da modernidade.

Já o segundo revela a importância do esquecimento na atual era informacional, especialmente após o surgimento da internet, principal responsável por revolucionar os meios de comunicação. Os efeitos são tão marcantes que afetaram antigos hábitos e costumes. A maneira como o mundo se relaciona vem mudando desde o seu nascimento. 
Seu caráter democrático e imediatista imprimiu maior velocidade às interações sociais. 0 ciberespaço possui características próprias - velocidade, atemporalidade e acessibilidade que influem diretamente no tratamento dispensado aos dados virtuais, visto que permitem de certa forma a condenação perpétua pelos erros do passado. As características da internet reforçam a necessidade de um direito ao esquecimento.

Mas há outro fator capaz de impulsionar o uso indiscriminado de informações, menos em razão de sua relevância do que seu valor econômico. Especializado no processamento e interpretação de dados virtuais, o Big Data utiliza as informações deixadas pelos usuários na internet em prol do capitalismo. Com base nos rastros virtuais, é possível descobrir uma infinidade de coisas acerca do comportamento do consumidor, usadas para elaborar desde planos estratégicos até marketing para públicos específicos. A quantidade de dados é o motor que faz o sistema funcionar. Se alguma coisa, como o direito ao esquecimento, ameaça de alguma forma reduzi-la, deve ser combatida. É o que de fato acontece com os mecanismos de busca, que se recusam a aceitar qualquer interferência em seu principal atrativo: a massa gigantesca de dados.

Abordou-se logo adiante a questão do embate entre o direito à privacidade e a liberdade de imprensa. A matéria rende bastante polêmica em função de sua importância, visto que ambas são garantias imprescindíveis para uma sociedade democrática, mas às vezes encontram dificuldades em coexistir. Numa demonstração de sabedoria, a Assembleia Constituinte de 1998 disciplinou a matéria e estabeleceu limites à liberdade de imprensa, guiados pelo respeito aos direitos da personalidade. Se extrapolar o limite do razoável, e atingir a privacidade do indivíduo, nada melhor do que responsabilizar o agente pelos danos praticados. Com isso em mente, a Carta Magna fixou a dignidade da pessoa humana como limite constitucional a liberdade de imprensa, sob pena de perdas e danos e direito de resposta.

A efetivação do direito ao esquecimento foi analisada no penúltimo tópico, em que se constata a total viabilidade do instituto, a despeito das críticas dos defensores de uma liberdade de imprensa absoluta. As duas garantias são perfeitamente compatíveis - se nenhuma extrapolar os limites constitucionais -, devido à fixação de critérios rigorosos, com os quais é possível reprimir eventuais ofensas aos direitos da personalidade ou tentativas de censura disfarçadas. Por conseguinte, o direito de ser esquecido é aplicável ao meio virtual sem maiores restrições, visto que afeta apenas as ferramentas de busca, propiciadoras da eternização dos dados virtuais, sem atingir o site original em que o conteúdo está hospedado. São situações distintas, que favorecem a implementação do instituto no campo virtual. 
Assim, a alegação de censura no meio virtual em função da aplicação do direito de ser esquecido é uma falácia. O único elemento afetado são as ferramentas de busca, enquanto a fonte original permanece ilesa. Se algum pesquisador, ou quem quer que seja, manifestar interesse pelo assunto, poderá acessar diretamente a matéria no site original. 0 que refuta de vez a tese de que o direito ao esquecimento representa uma ameaça a história, que seria manipulada pelos pedidos de remoção.

Portanto, se sua aplicação em nada representa ameaça à liberdade de imprensa, nem ao patrimônio histórico, tampouco à narração real dos fatos; se constitui instrumento jurídico essencial para proteção dos direitos da personalidade na atual era informacional, é razoável concluir favoravelmente à implementação do direito ao esquecimento, dada sua importância e aceitação pela doutrina e jurisprudência.

\section{Referências}

ALBERS, Marion. A imprensa também tem limites. Revista PUCRS, no 173, março. 2015. p.30-31.

BRASIL. STJ. REsp n. 1.334.097/RJ. Rel.Min. Luís Felipe Salomão. Quarta Turma. Julgamento em 28.05.2013.

. STJ. REsp n. 1.335.153/RJ. Rel. Min. Luís Felipe Salomão. Quarta Turma. Julgamento em 28.05/2009.

BURGOS, Pedro. Google, me esquece. Disponível em: <http://www.revistagalileu.globo.com.br>. Acesso em: 01 abril. 2016.

CUNHA, Carolina. Big Data: como a inteligência de dados vai mudar nosso dia a dia. Disponível em http://www.vestibular.uol.com.br. Acesso em: 01 abril. 2016.

INNERARITY, Daniel. O novo espaço público. Lisboa: Teorema, 2006.

LEMOS, Ronaldo. Direito ao esquecimento é mais veneno do que remédio. Disponível em: <http://www.folha.uol.com.br>. Acesso em: 01 março. 2016.

' Ronaldo. Esquecer o direito de ser esquecido. Disponível em: <http://www.folha.uol.com.br>. Acesso em: 01 março. 2016.

LÉVY, Pierre. Cibercultura. São Paulo: Editora 34, 1999.

MENDES, Gilmar Ferreira. Direitos fundamentais e controle de constitucionalidade. São Paulo: Celso Bastos, Editor, 1998, p.86.

SOARES, Elisângela Campos de Melo. Internet, memória onipresente - Direito ao esquecimento versus Direito à informação. Artigo Científico. ESPM/SP, São Paulo, 2014. 
MENDES, Gilmar Ferreira; BRANCO, Paulo Gustavo Gonet. Curso de Direito Constitucional. 7. ed. São Paulo: Saraiva, 2012.

OLIVEIRA, Eulina. Com big data, empresas e governos 'preveem' futuro. Disponível em: <http://www.folha.uol.com.br>. Acesso em: 06 maio. 2016

PASSOS NETO, João dos; PINHEIRO, Denise. Liberdade de informar e direito à memória Uma crítica a ideia do direito ao esquecimento. Revista Novos Estudos Jurídicos - Eletrônica, Vol. 19 - n. 3 - set-dez 2014.

REVISTA PUCRS. São Paulo: PUCRS, no 173, março. 2015.

SCARLET, Ingo. A imprensa também tem limites. Revista PUCRS, no 173, março. 2015. p.3031.

SILVA, José Afonso da. Curso de direito constitucional positivo. 25. ed. São Paulo: Malheiros, 2013.

SUPERIOR TRIBUNAL DE JUSTIÇA (STJ). Enunciado no 531, Conselho da Justiça Federal (CJF),

23 de Abril de 2013. Disponível em: http://www.cjf.jus.br/cjf/CEJCoedi/jornadascej/vijornada.pdf>. Último acesso: 01 abril. 2014.

Recebido em 11/10/2016

Aceito em 20/01/2017 